\title{
Roxane Martin, La Féerie romantique sur les scènes parisiennes (1791-1864)
}

Lise Sabourin

\section{(2) OpenEdition}

\section{Journals}

Édition électronique

URL : http://journals.openedition.org/studifrancesi/8947

DOI : 10.4000/studifrancesi.8947

ISSN : 2427-5856

Éditeur

Rosenberg \& Sellier

\section{Édition imprimée}

Date de publication : 1 octobre 2008

Pagination : 465-466

ISSN : 0039-2944

\section{Référence électronique}

Lise Sabourin, « Roxane Martin, La Féerie romantique sur les scènes parisiennes (1791-1864) », Studi

Francesi [En ligne], 155 (LII | II) | 2008, mis en ligne le 30 novembre 2015, consulté le 11 janvier 2021 URL : http://journals.openedition.org/studifrancesi/8947 ; DOI : https://doi.org/10.4000/studifrancesi. 8947

Ce document a été généré automatiquement le 11 janvier 2021.

\section{cc) (†) $\ominus$}

Studi Francesi è distribuita con Licenza Creative Commons Attribuzione - Non commerciale - Non opere derivate 4.0 Internazionale. 


\title{
Roxane Martin, La Féerie romantique sur les scènes parisiennes (1791-1864)
}

\author{
Lise Sabourin
}

\section{RÉFÉRENCE}

ROXANE MARTIN, La Féerie romantique sur les scènes parisiennes (1791-1864), Paris, Honoré

Champion, 2007, pp. 693.

1 Cet ouvrage, issu d'une thèse de doctorat couronnée du Prix d'esthétique théâtrale Georges-Jamati 2004, scrute les contours d'un genre et d'une esthétique trop négligés par une recherche parfois encore livrée au manichéisme entre tragique et comique ou à son dépassement par le seul drame romantique. Si Roxane Martin, s'appuyant dans son introduction sur la vision transhistorique de Gusdorf, définit a priori un peu largement l'épithète «romantique» de son titre, elle en restreint fort heureusement le champ aux ouvrages de féerie représentés de la loi libératrice des privilèges dramatiques de 1791 à la liberté industrielle des théâtres en 1864, justifiant ainsi pleinement son intitulé et son projet.

2 Elle cerne en effet sur un répertoire (voir l'index des auteurs et interprètes, la bibliographie et la table des illustrations, pp.479-684) de plus de sept cents pièces souvent jouées, accompagnées de mille cinq cents documents liés à leur représentation (maquettes de décors, manuscrits de censure, livrets de mise en scène, partitions d'orchestre, iconographies) le rôle important qu'a joué pour l'esthétique théâtrale du $\mathrm{XIX}^{\mathrm{e}}$ siècle le passage du littéraire au spectaculaire dans la recherche du pouvoir dramatique sur scène, face aux codifications toujours remises à l'ordre du jour par les doctes comme par leurs contestataires. Bref, ce que Gautier a appelé le «théâtre oculaire» comme creuset des réflexions génériques et esthétiques.

3 La féerie, qui exerce son attrait de "grand spectacle» depuis le XVII ${ }^{\mathrm{e}}$ siècle, renouvelée dans des sens divers par le théâtre forain au $\mathrm{XVIII}^{\mathrm{e}}$, n'accède véritablement à son autonomie que sous le Directoire, connaît grand succès sous la Restauration et la 
Monarchie de Juillet, se formalise sous le Second Empire et s'éteint après la Commune. Roxane Martin discerne les deux grandes étapes de son évolution: d'abord placée au cœur des débats sur les genres (1791-1830, $1^{\text {ère }}$ partie, pp. 21-229), la féerie s'érige ensuite en une spécifique esthétique du spectaculaire $\left(1831-1864,2^{\mathrm{e}}\right.$ partie, pp. 231-470).

4 Après Diderot, les auteurs de féeries de la décennie révolutionnaire recherchent une nouvelle grammaire théâtrale à l'aide de la musique, de la pantomime, du ballet et des décors, en un rééquilibrage populaire de l'impact du spectacle sur les préoccupations textuelles qui ne laissera indifférents à l'époque romantique ni les acteurs ni les décorateurs, ni les dramaturges ni les librettistes, habitués à intervenir dans des créations théâtrales de nature fort diverse. Face à l'aboutissement moral du mélodrame comme à l'écriture satirique du vaudeville, la féerie oscille en 1810-1820 entre manichéisme des amours (contrariées mais finalement heureuses) et burlesque (parodiant ses propres recettes langagières). Cette voie comique, à partir des Petites Danaïdes ou les 99 victimes (1819), incite la féerie à s'organiser en tableaux codifiant la quête amoureuse, lesquels peu à peu aboutissent à une mécanique de changements de décors se substituant à l'intrigue. Son incohérence même deviendra sous le Second Empire consubstantielle à la dimension parodique de la féerie, livrant merveilleux et saisissement à la surenchère, notamment par la récupération des «clous» anciens et la caricature des conventions. Ce mécanisme figé, accentué par la prolifération parallèle aux textes de féeries de leurs livrets de mise en scène et de leurs partitions orchestrales qui jette la confusion, explique sa disparition, non sans annoncer pourtant Ionesco, Jarry et Antoine qui s'en sont nourris.

5 On comprend que cet ouvrage, pionnier sur le genre, est riche de l'étude de multiples féeries, tant inconnues que dues à des auteurs célèbres (voir les chapitres sur Nodier, Hugo et Flaubert), tout en nous apportant une réflexion générique et esthétique d'ensemble utile à quiconque veut réfléchir, au-delà des cloisonnements faciles, sur la dramaturgie romantique. 